\title{
Extended application of the Equivalent Mortar Volume mix design method for recycled aggregate concrete
}

\author{
Emmanuel E. Anike ${ }^{1}$, Messaoud Saidani ${ }^{2}$, Adegoke O. Olubanwo ${ }^{3}$, Mark Tyrer ${ }^{4}$ \\ ${ }^{1,4}$ Centre for Research in the Built and Natural Environment, Coventry University \\ 3 Gulson Road, Coventry CV1 2JH, United Kingdom. \\ anikee@uni.coventry.ac.uk; ac5015@coventry.ac.uk \\ ${ }^{2,3}$ School of Energy, Construction \& Environment, Coventry University \\ Priory Street, Coventry, CV1 5FB, United Kingdom. \\ m.saidani@coventry.ac.uk; adegoke.olubanwo2@coventry.ac.uk;
}

\begin{abstract}
This paper presents the study carried out using the extended Equivalent Mortar Volume (EMV) mix design technique, for concrete made of recycled aggregates (RA) and steel fibre (SF). The expansion of the EMV approach is necessary to encourage the use of fine recycled aggregates (FRA) in concrete manufacture. To this end, the same replacement ratio obtained for coarse recycled aggregates (CRA) using the EMV principles, was applied to the FRA for concrete production. Furthermore, SF was added to improve the mechanical behaviour of RA-concrete developed with this method. Altogether, four mixes were developed using a constant waterto-cement ratio of 0.42 thus: reference mix labelled conventional concrete $(\mathrm{CC})$ prepared with natural aggregates (NA); crushed aggregate concrete (CAC) mix designed with the conventional method and made of 100\% RA; blended aggregate concrete (BAC) mix prepared with the EMV guide and composed of both NA and RA; and steel fibre-reinforced blended aggregate concrete (SFRBAC) mix prepared by adding optimum SF to the BAC mix. Then, cubical, cylindrical and prismatic specimens were produced from the mixes to investigate different properties of concrete. The experimental results show that the mechanical properties of concrete are not adversely affected by the presence of FRA. Also, the EMV mix design provision offers a better result than its companion conventional approach, even with about $30 \%$ reduction in cement content. The addition of SF mainly controlled crack development and induced a ductile failure mode.
\end{abstract}

Keywords: Fine recycled aggregates, Steel fibre, Mix design, Equivalent mortar volume, crack development.

\section{Introduction}

Recycled aggregates (RA) has become popular globally. This is not just due to incessant demolition of concrete structures, but for its potentials to replace natural aggregates (NA) in many civil engineering works. The consideration of concrete rubble as a useful material in the construction industry is prompted by the environmental concerns arising from the handling of construction and demolition waste (CDW) and the depletion of natural aggregate. Wang et al. [1] upheld that the demolition of concrete structures will continue from time to time. The obvious reason for this is to meet the accommodation needs for population growth and design specifications appropriate for modern structures. Consequently, more and more CDW are generated and sent to landfills for deposition. But CDW is composed of up to $40 \%$ concrete [2], therefore, recycling this proportion of construction debris into aggregate in new concrete would serve as a huge relief to the current problems [3]. The major hindrance to the adoption of RA in concrete production is in the mix design appropriate for RA-concrete [4][6]. This is as a result of the dry mortar clinging to the RA which makes it a heterogenous material.

Hence, this study adopts the Equivalent Mortar Volume (EMV) mix proportioning technique developed by Fathifazl et al. [6] to investigate the properties of concrete produced with RA obtained from a precast waste. The EMV method is modified by the inclusion of fine recycled aggregates (FRA) and steel fibre (SF) for concrete manufacture. It is worth noting that only coarse recycled aggregates (CRA) was used by the pioneers of the EMV method, but in the present research, the same ratio obtained for CRA by the design principles was adopted for the FRA. The incorporation of FRA in concrete manufacture will ensure a more holistic measure in saving the environment and natural resources, as there are more fines than the chunks when concrete rubble is crushed. The incorporation of SF is to improve strength and mostly to control crack propagation. Therefore, the specific objectives of this study are: (i) to examine the extent of variation in the properties of 
RA-concretes with and without SF and prepared using the EMV approach, (ii) to compare the characteristics of RA-concretes prepared with the conventional and EMV methods to those of the reference mix composed entirely of NA.

\section{Materials and method}

\section{1. Materials}

The aggregates (natural and recycled), cement and superplasticizer used in this research were provided by a precast beam production company. According to the data provided by the company, their beams are made of concrete of approximately 40MPa cube compressive strength, obtained after 24 hours of cast. The condemned products were crushed to a suitable size in a Rubble Master Compact Crusher and supplied together with other materials used for the present study. The maximum size of the coarse aggregate used is $14.00 \mathrm{~mm}$ and that of the fine aggregate is $4.75 \mathrm{~mm}$, and their properties are given in Table 1. Rapid CEM I Portland cement conforming to BS EN 197-1 [7] standard was employed. The superplasticizer complies with the BS EN 934-2 [8] specification. Special SF having a tensile strength of 1900MPa was ordered from China for this research. This is because, the idea of using SF is to compensate for strength and to restrain cracks in RA-concrete. Undulated SF of $60 \mathrm{~mm}$ length and $1.0 \mathrm{~mm}$ diameter (resulting to an aspect ratio of 60) was adopted. Clean water obtained from the supply mains in the laboratory was used.

Table 1: Properties of aggregates.

\begin{tabular}{|c|c|c|c|c|c|c|c|c|c|c|}
\hline \multirow{3}{*}{ Property } & \multicolumn{3}{|c|}{ FNA } & \multicolumn{3}{|c|}{ FRA } & \multicolumn{2}{|c|}{ CNA } & \multicolumn{2}{|c|}{ CRA } \\
\hline & \multicolumn{3}{|c|}{ Size fraction $(\mathrm{mm})$} & \multicolumn{3}{|c|}{ Size fraction $(\mathrm{mm})$} & \multicolumn{2}{|c|}{ Size fraction $(\mathrm{mm})$} & \multicolumn{2}{|c|}{ Size fraction $(\mathrm{mm})$} \\
\hline & $\begin{array}{c}0.075- \\
0.57\end{array}$ & $\begin{array}{l}0.57- \\
2.47\end{array}$ & $\begin{array}{r}2.47- \\
4.75\end{array}$ & $\begin{array}{c}0.075- \\
0.57\end{array}$ & $\begin{array}{c}0.57- \\
2.47\end{array}$ & $\begin{array}{r}2.47- \\
4.75 \\
\end{array}$ & $\begin{array}{l}4.75- \\
10.00\end{array}$ & $\begin{array}{c}10.00- \\
14.00\end{array}$ & $\begin{array}{l}4.75- \\
10.00\end{array}$ & $\begin{array}{l}10.00- \\
14.00\end{array}$ \\
\hline Specific gravity (SSD) & 2.63 & 2.60 & 2.52 & 2.10 & 2.20 & 2.34 & 2.63 & 2.64 & 2.42 & 2.42 \\
\hline Water absorption (\%) & 0.6 & 1.1 & 1.4 & 18.1 & 12.1 & 8.9 & 0.9 & 0.6 & 5.4 & 5.1 \\
\hline Fineness modulus & \multicolumn{3}{|c|}{2.87} & \multicolumn{3}{|c|}{2.71} & \multicolumn{2}{|c|}{4.08} & \multicolumn{2}{|c|}{3.54} \\
\hline Voids content $(\%)$ & \multicolumn{3}{|c|}{-} & \multicolumn{3}{|c|}{-} & 41 & 39 & 43 & 44 \\
\hline Dry-rodded density $\left(\mathrm{kg} / \mathrm{m}^{3}\right)$ & \multicolumn{3}{|c|}{-} & \multicolumn{3}{|c|}{-} & 1543 & 1586 & 1300 & 1293 \\
\hline Attached mortar volume (\%) & \multicolumn{3}{|c|}{ - } & \multicolumn{3}{|c|}{ - } & - & - & 51 & 52 \\
\hline
\end{tabular}

Note: SSD = Saturated surface-dry

\section{2. Method}

The crushed concrete obtained from the precast beams was first sieved into different grades, to obtain FRA and CRA. The FRA was sieved into three categories thus; $0.075-0.57 \mathrm{~mm}, 0.57-2.47 \mathrm{~mm}$ and $2.47-4.75 \mathrm{~mm}$, while the CRA was categorized into two viz; $4.75-10.00 \mathrm{~mm}$ and $10.00-14.00 \mathrm{~mm}$. Similarly, fine natural aggregate (FNA) and coarse natural aggregate (CNA) were sieved to the same grades. Then, the characteristics of all the aggregates were determined according to grade as given in Table 1. Thereafter, four mixes were developed to achieve the set objectives as follows: (i) Conventional concrete (CC) mix referred to as the reference mix made entirely of NA and designed using the American Concrete Institute (ACI) principles [9], (ii) Crushed aggregate concrete (CAC) mix made up of 100\% RA and prepared with the same ACI provisions, (iii) Blended aggregate concrete (BAC) mix consisting of 60\% RA and 40\% NA and proportioned with the EMV method [6], (iv) Steel fibre-reinforced blended aggregate concrete (SFRBAC) mix produced by adding SF to the BAC mix. Fine and coarse aggregates were added to concrete in the ratio 3:2:1 and 7:3 respectively, in line with the grades aforementioned.

Optimization of SF was first of all carried out by integrating different percentages $(0.25 \%, 0.5 \%$ and $0.75 \%)$ in the BAC mix, of which, $0.5 \%$ was selected as the candidate based on the compressive strength of the $100 \mathrm{~mm}$ cube-specimens tested after 7 days of curing in water. The use of compression test was to determine whether or not the addition of SF to RAconcrete prepared with the EMV technique, improves strength. This was deemed appropriate as previous researchers have reported conflicting results on the contribution of SF to compressive strength of concrete mix designed with the orthodox method. Finally, all the four mixes were designed as shown in Table 2 to a target strength of 40MPa at 28 days. Five $100 \mathrm{~mm}$ cubes (for density and compressive strength), three $100 \times 200 \mathrm{~mm}$ cylinders (for water absorption), three $150 \times 300 \mathrm{~mm}$ cylinders (for splitting tensile strength) and two $100 \times 100 \times 500 \mathrm{~mm}$ prisms (for flexural strength) were manufactured from 
each mix and tested after curing by water immersion. Concrete properties were tested according to the following standards: hardened density [10], compressive strength [11], splitting tensile strength [12], flexural strength of the unreinforced concretes [13], flexural strength of the SF-reinforced concrete [14] and water absorption [15].

Table 2: Composition of concrete mixes.

\begin{tabular}{ccccccccccc}
\hline \multirow{2}{*}{ Mix ID } & $\begin{array}{c}\text { RA content } \\
(\%)\end{array}$ & \multicolumn{8}{c}{ Mix Proportion $\left(\mathrm{kg} / \mathrm{m}^{3}\right)$} & \multirow{2}{*}{ w/c } \\
\cline { 3 - 10 } & & Water & Cement & FNA & FRA & CNA & CRA & SP & SF & \\
\hline CC & 0 & 213 & 507 & 707 & 0 & 856 & 0 & 1.27 & 0 & 0.42 \\
CAC & 100 & 213 & 507 & 0 & 534 & 0 & 754 & 1.52 & 0 & 0.42 \\
BAC & 60 & 153 & 364 & 203 & 305 & 493 & 754 & 7.28 & 0 & 0.42 \\
SFRBAC & 60 & 153 & 364 & 203 & 305 & 493 & 754 & 12 & 39.25 & 0.42 \\
\hline
\end{tabular}

Note: $\mathrm{SP}=$ superplasticizer, $\mathrm{w} / \mathrm{c}=$ water-to-cement ratio

\section{Results and discussion}

\section{1. Hardened density}

Overall, concrete manufactured using NA is denser than those containing RA. According to Table 3 , the hardened density of concrete made with full replacement of NA (that is, CAC), was reduced by up to $8 \%$ when compared to that of the normal concrete (CC). This is due to mortar adhering to the RA, which is known to be a lightweight and porous material. But the use of the EMV mix proportioning method reduced the effect to just $1 \%$ and further reduction to $0.8 \%$ when SF is used together with this method.

\section{2. Compressive strength}

The compressive strength of the samples produced from the four mixes, determined at different ages, is presented in Fig. 1. The results show that all the samples met the design target strength and that a number of factors influence this property of concrete. Firstly, it is obvious that the CC gave the highest compressive strength at all ages compared to the concrete of other mixes. At maturity age (28 days), the CC showed about 19\%, 7\% and 13\% higher strength than its comparable CAC, BAC and SFRBAC, respectively. This implies that the presence of RA reduces strength and the degree of reduction depends on the quantity of RA used. Secondly, it can be deduced from Fig. 1 that mix proportioning method significantly impacts on concretes prepared with RA. The mixes containing RA, designed with the EMV technique, showed up to $12 \%$ higher strength than their companion mix prepared with the conventional method. This is impressive, as the BAC and SFRBAC mixes utilized approximately $30 \%$ lesser amount of cement relative to that of CAC mix. This performance can be attributed to greater amount of superplasticizer present in BAC and SFRBAC mixes, resulting in a better quality of mortar [6] and a more homogeneous parking density [16]. Comparatively, however, the BAC showed a superior compressive strength than the SFRBAC. This implies that the addition of SF causes a reduction effect on the compressive strength of RA-concrete proportioned with the EMV approach. Similar effect of SF on the compressive strength of concrete has been reported in the past, although the studies were carried out using the traditional mix design method for NA [17]-[20]. 


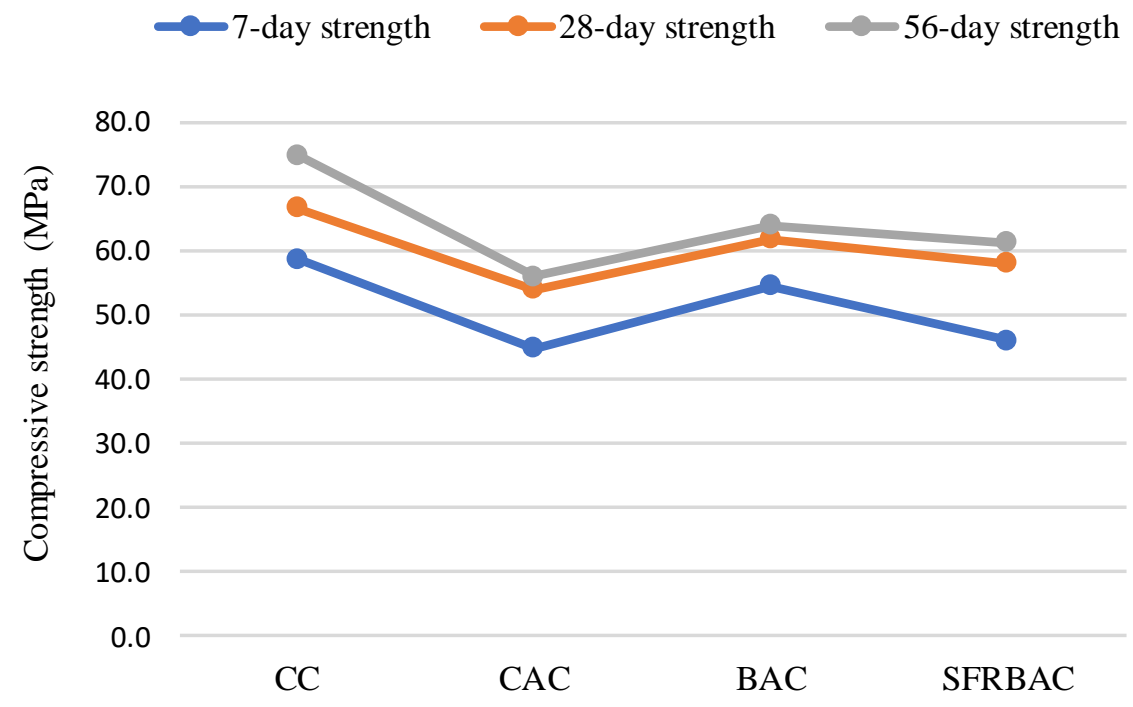

Fig. 1: Compressive strength of concrete at different ages.

\section{3. Splitting tensile strength}

The outcome of the splitting tensile strength of all the concrete mixes examined is illustrated in Fig. 2. Generally, concretes consisting of RA (that is, CAC, BAC and SFRBAC) exhibited greater tensile strength values than that of the reference mix produced with conventional aggregates, even with $100 \%$ replacement of NA. This finding agrees with those of Afroughsabet et al. [21], Malesev et al. [22] and Etxeberria et al. [23] who reported that concretes made from RA have superior tensile strength compared to conventional concrete, in spite of the replacement levels. It then follows that the splitting tensile strength depends on the quality of RA rather than its quantity. The EMV method presents additional positive effect of approximately 5\% over its parallel conventional method. However, there is a nominal reduction of about $2 \%$ in the tensile strength of SFRBAC compared to that of BAC. This is because the incorporation of SF reduced the quality of SFRBAC paste, in comparison to that of BAC mix. Nonetheless, the role of the SF is mainly to bridge cracking propagation, thus engendering a ductile failure mode. Hence, it was observed in this test that, whereas the specimens of other mixes failed by splitting into two, those of SFRBAC mix did not split at failure but only nearly invisible cracks occurred as revealed in Fig. 3. 


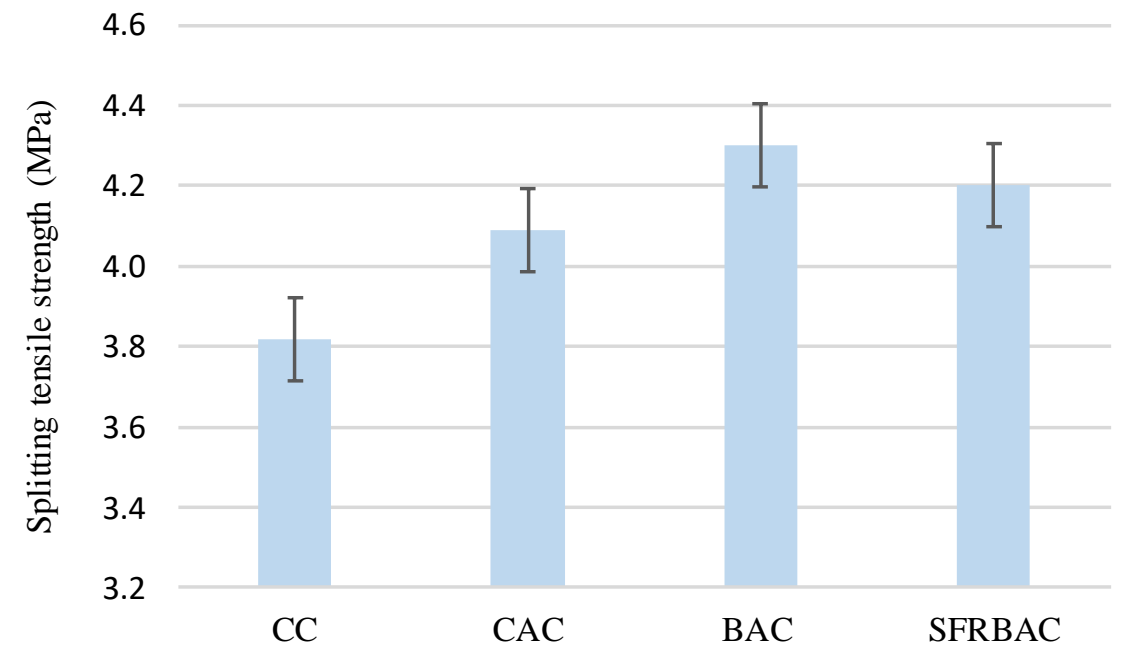

Fig. 2: Splitting tensile strength of different mixes at 28 days.

(a)
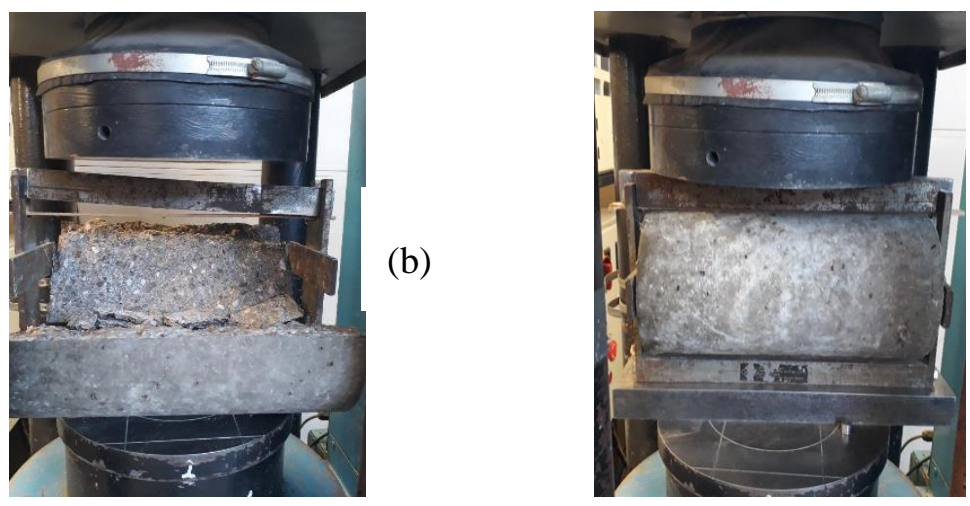

Fig. 3: Splitting tensile strength test failure mode: (a) Unreinforced concretes (b) SFRBAC.

\section{4. Flexural strength}

Table 3 shows that the flexural strength of samples from the CC mix is higher than the ones of other mixes containing RA. However, the results demonstrate that this concrete property is affected largely by the quality of paste than the type of aggregate. It can also be deduced that the quantity of RA has no consequential effects on the flexural strength. This aligns with the findings of some authors in the literature [24], [25]. In terms of design method, there is only around 3\% variation in the flexural strength of concretes produced using the ACI and EMV methods, in favour of the former. Albeit, it is essential to point out that the mixes resulting from the EMV guide, used an appreciably lower cement content compared to its corresponding ACI style. Furthermore, the shortfall observed for the SFRBAC samples can be attributed to the inferiority of their mortar relative to that of the BAC.

\section{5. Water absorption capacity}

The water absorption capacity of the concretes produced from the mixes investigated is presented in Table 3 . The values obtained show that RA has a devastating effect on this durability property of concrete. Both RA content and the method of mix design contributed to the observed effect. While CAC mix showed up to $45 \%$ higher absorption compared to the CC mix, the difference between the reference mix and BAC and SFRBAC mixes is marginal. The lower absorption capacity of 
BAC and SFRBAC mixes relative to that of CAC mix is as a result of the reduced amount of RA engendered by the use of EMV technique. It is clear from Table 3, that the inclusion of SF has no effects on the water absorption of the concrete.

Table 3: Some properties of concretes of various mixes at 28 days.

\begin{tabular}{cccc}
\hline Mix ID & $\begin{array}{c}\text { Hardened } \\
\text { density } \\
\left(\mathrm{kg} / \mathrm{m}^{3}\right)\end{array}$ & $\begin{array}{c}\text { Flexural } \\
\text { strength } \\
(\mathrm{MPa})\end{array}$ & $\begin{array}{c}\text { Water } \\
\text { absorption } \\
(\%)\end{array}$ \\
\hline CC & 2370 & 5.04 & 3.1 \\
CAC & 2180 & 4.89 & 5.6 \\
BAC & 2340 & 4.73 & 3.4 \\
SFRBAC & 2350 & 4.20 & 3.4 \\
\hline
\end{tabular}

\section{Conclusion}

The expanded Equivalent Mortar Volume (EMV) mix design method for concrete produced with recycled aggregates (RA) is presented and discussed in this document. The following conclusions are drawn:

(i) The use of the EMV mix design approach reduces cement content to about $30 \%$ compared to its corresponding American Concrete Institute (ACI) method, with no devastating impact on concrete properties.

(ii) RA volume has a significant negative influence on both compressive strength and water absorption capacity of concrete, but not on the flexural and tensile strengths. Overall, the splitting tensile strength of samples produced with RA performed better than those of reference mix made of natural aggregates (NA), regardless of replacement ratio. This is because of the more angularity of the aggregates from crushed concrete (that is, RA) than the normal aggregates. This finding shows that splitting tensile strength depends on the quality of RA and not on its quantity.

(iii) The addition of steel fibre affected the quality of the mix proportioned by the EMV method as observed in the decrease in compressive and flexural strengths of the resulting concrete. Although, it should be noted that the SF mainly controls crack propagation and improves the ductility of the specimens.

(iv) Generally, RA sourced from a precast waste (of similar quality with the one used in this study) can conveniently substitute NA in the production of concrete fit for structural purposes, provided the EMV mix design method is used. Furthermore, the use fine recycled aggregate is of no consequential effect on the mechanical properties of concretes investigated.

\section{Acknowledgements}

The authors acknowledge the managements of Litecast Homefloors Ltd., United Kingdom and Dalian HARVEST Metal Fibres Co. Limited, China for supplying the materials used for this research free of charge.

\section{References}

[1] L. Wang, J. Wang, X. Qian, P. Chen, Y. Xu, and J. Guo, "An environmentally friendly method to improve the quality of recycled concrete aggregates," Constr. Build. Mater., vol. 144, pp. 432-441, 2017.

[2] N. D. Oikonomou, "Recycled concrete aggregates," Cem. Concr. Compos., vol. 27, no. 2, pp. 315-318, Feb. 2005.

[3] E. E. Anike, M. Saidani, E. Ganjian, M. Tyrer, and A. O. Olubanwo, "The potency of recycled aggregate in new concrete: a review," Constr. Innov., vol. 19, no. 4, pp. 594-613, 2019.

[4] R. V. Silva, J. de Brito, and R. K. Dhir, "Availability and processing of recycled aggregates within the construction and demolition supply chain: A review," J. Clean. Prod., vol. 143, pp. 598-614, 2017.

[5] P. K. Gupta and R. Bhatia, "Study of Engineering Properties of Recycled Concrete Aggregate Concrete," $i$-manager's J. Struct. Eng., vol. 2, no. 1, pp. 20-27, 2013.

[6] G. Fathifazl, A. Abbas, A. G. Razaqpur, O. B. Isgor, B. Fournier, and S. Foo, "New Mixture Proportioning Method 
for Concrete Made with Coarse Recycled Concrete Aggregate," J. Mater. Civ. Eng., vol. 21, no. 10, pp. 601-611, 2009.

[7] BS EN 197-1, "Part 1: Composition, specifications and conformity criteria for common cements," 2011.

[8] BS EN 934-2:2009 +A1:2012, "Admixtures for concrete , mortar and grout: Part 2: Concrete admixtures — Part 2: Concrete admixtures - Definitions, requirements, conformity, Definitions, requirements, conformity, marking and labelling marking," 2012.

[9] ACI Committee 211, "ACI 211. 1-91 Standard Practice for Selecting Proportions for Normal, Heavyweight, and Mass Concrete," 2009.

[10] BS EN 12390-7, "Testing hardened concrete Part 7: Density of hardened concrete," 2009.

[11] BS EN 12390-3, "Testing hardened concrete- Part3: Compressive strength of test specimens," vol. 3, no. 1, pp. 420457, 2009.

[12] BS EN 12390-6, "Testing hardened concrete- Part 6: Tensile splitting strength of test specimens,” 2009.

[13] ASTM C78/C78M - 18, "Standard Test Method for Flexural Strength of Concrete ( Using Simple Beam with ThirdPoint Loading ),” 2018.

[14] ASTM C1609/C1609M - 12, "Standard Test Method for Flexural Performance of Fiber-Reinforced Concrete ( Using Beam With Third-Point Loading )," 2012.

[15] BS 1881-122, "Testing concrete Part 122: Method for determination of water absorption," Br. Stand. Int., 2011.

[16] H. Moosberg-Bustnes, B. Lagerblad, and E. Forssberg, "The function of fillers in concrete," Mater. Struct. Constr., vol. 37, no. 266, pp. 74-81, 2004.

[17] F. Altun, T. Haktanir, and K. Ari, "Effects of steel fiber addition on mechanical properties of concrete and RC beams," Constr. Build. Mater., vol. 21, no. 3, pp. 654-661, 2007.

[18] B. Boulekbache, M. Hamrat, M. Chemrouk, and S. Amziane, "Flexural behaviour of steel fibre-reinforced concrete under cyclic loading," Constr. Build. Mater., vol. 126, pp. 253-262, 2016.

[19] B. Boulekbache, M. Hamrat, M. Chemrouk, and S. Amziane, "Flowability of fibre-reinforced concrete and its effect on the mechanical properties of the material," Constr. Build. Mater., vol. 24, no. 9, pp. 1664-1671, 2010.

[20] S. Erdem, A. R. Dawson, and N. H. Thom, "Microstructure-linked strength properties and impact response of conventional and recycled concrete reinforced with steel and synthetic macro fibres," Constr. Build. Mater., vol. 25, no. 10, pp. 4025-4036, 2011.

[21] V. Afroughsabet, L. Biolzi, and T. Ozbakkaloglu, "Influence of double hooked-end steel fibers and slag on mechanical and durability properties of high performance recycled aggregate concrete," Compos. Struct., vol. 181, pp. 273-284, 2017.

[22] M. Malešev, V. Radonjanin, and S. Marinković, "Recycled concrete as aggregate for structural concrete production," Sustainability, vol. 2, no. 5, pp. 1204-1225, 2010.

[23] M. Etxeberria, E. Vázquez, A. Marí, and M. Barra, "Influence of amount of recycled coarse aggregates and production process on properties of recycled aggregate concrete," Cem. Concr. Res., vol. 37, no. 5, pp. 735-742, 2007.

[24] I. S. Ignjatović, S. B. Marinković, Z. M. Mišković, and A. R. Savić, "Flexural behavior of reinforced recycled aggregate concrete beams under short-term loading," Mater. Struct., vol. 46, no. 6, pp. 1045-1059, 2013.

[25] W.-C. Choi, H.-D. Yun, and S.-W. Kim, "Flexural performance of reinforced recycled aggregate concrete beams," Mag. Concr. Res., vol. 64, no. 9, pp. 837-848, 2012. 